\title{
From the Perspective of Loneliness and Cognitive Absorption Internet Addiction as Predictor and Predicted
}

\author{
Vehbi Celik \& Etem Yesilyurt \\ Mevlana University, TURKEY \\ Ozgen Korkmaz \\ Amasya University, TURKEY \\ Ertugrul Usta \\ Necmettin Erbakan University, TURKEY \\ Received 19 September 2013; accepted 11 April 2014
}

\begin{abstract}
In this research internet addiction has been dealt with as predictor and predicted variable, this situation has been analyzed from the perspectives of loneliness and cognitive absorption and a tangible model has been put forth. Participant group has been constituted by 338 teacher candidates. Research data were collected using loneliness scale $(\alpha=.96)$, cognitive absorption scale $(\alpha=.90)$ and internet addiction scale $(\alpha=.95)$. On the data that was obtained; structural equation model were used. As a result: Loneliness levels of candidate teachers have significant and positive direction effect on internet addiction. On the other hand internet addiction of teacher candidates affects their loneliness levels in positive direction and significantly.
\end{abstract}

Keywords: Loneliness, cognitive absorption, internet addiction, teacher training.

\section{INTRODUCTION}

Information technologies are the technologies that constitute basic dynamics of information society. With these technologies a brand new society structure has emerged. However, it is inevitable that these technologies that constitute the fundamentals of brand new society have some negative effects, as well (Kelleci, 2008; Khasawneh \& Al-Awidi, 2008). It can be said that among these negativities internet addiction problem is in the lead. In recent years internet addiction has been associated with various psychological problems and started to be tackled as a psychological problem in science world. Particularly educators, psychological counselors, psychologists and psychiatrists have

Correspondence to: Ozgen Korkmaz; Amasya University, Technology Faculty, Department of Computer Engineering, Amasya, TURKEY

E-mail: ozgenkorkmaz@gmail.com

doi: 10.12973/eurasia.2014.23560a gravitated towards various researches about the matter (Jiang \& Leung, 2012; Xu et all., 2012; Young, 2006; Orhan \& Akkoyunlu, 2004; Morahan- Martin \& Schumacher, 2000; Hawi, 2012). Despite this, the questions of what the internet addiction actually is and what its symptoms and causes are keep being discussed as yet and internet addiction is tried to be explained by different psychological concepts. In this study internet addiction is tried to be analyzed from the perspectives of "Loneliness" and "Cognitive Absorption", as well.

In general loneliness is stated as an undesired experience that is taken together with such concepts as sadness, anger, fear and concern (Russell, Peplau \& Cutrona, 1980; Ditomasso \& Spinner, 1997) and defined as not a pleasant subjective psychological situation that is formed as a result of inconsistency between individual's existing social relation and the social relation he desires (Peplau \& Perlman, 1982). In the literature it is possible to encounter many researches towards the existence of a relation between loneliness and internet addiction (Coget et all., 2002; Moody, 2001; Stepanikova et all., 2010; Amichai-Hamburge \& Ben-Artzi, 2003). 


\section{State of the literature}

- It is inevitable that these technologies that constitute the fundamentals of brand new society have some negative effects.

- It can be said that among these negativities internet addiction problem is in the lead.

- In recent years internet addiction has been associated with various psychological problems and started to be tackled as a psychological problem in science world. Particularly educators, psychological counselors, psychologists and psychiatrists have gravitated towards various researches about the matter

- Internet addiction can be predicted by loneliness, cognitive absorption

\section{Contribution of this paper to the literature}

- In the literature there are many researches with the subject matter of internet addiction, loneliness and cognitive absorption.

- However, no previous research has been found which statistically confirms the accuracy of the theoretical knowledge related to all three of these themes.

- In this research internet addiction has been dealt with as predictor and predicted variable

- Besides, in this research an answer has been sought for the question of "Does internet addiction more strongly predict loneliness or does loneliness more strongly predict internet addiction?"

When considered within this framework, it can be thought that loneliness and internet addictions can be predictor of each other. From the point of being able to make a definition of each of the two negative behaviors in question determining which one is the cause of the other, in other words determining if internet addiction causes loneliness or if loneliness causes internet addiction can make important contribution to the literature.

From the point of internet addiction or loneliness positive and negative experiences in lives are quite important from the viewpoint of prevention or development of the negative behavior. Agarwal and Karahanna (2000) define cognitive absorption as a deep addiction which stems from experiences related to information technologies. It is possible to say that at the foundation of cognitive absorption are the integrated experiences that individuals have gained in regards to technology. It is possible to encounter many researches about cognitive absorption situation's effect on perceptions and beliefs of individuals regarding getting benefit from information technologies (Webster \&
Hackley, 1997; Chen, 2000; Leong, 2011; Lin, 2009; Saade \& Bahli, 2005; Zhang et all., 2006). Besides, Saade and Bahli (2005) emphasize that cognitive absorption is significant predictor of individuals' technology usage and acceptance. When considered within this framework, it can be said that the experiences individuals have with information technologies can have important effect on their internet perception and internet usage, in other words, their cognitive absorption levels can be a predictor of their internet usage habits.

In the literature there are many researches with the subject matter of internet addiction, loneliness and cognitive absorption (Jiang \& Leung, 2012; Charlton \& Danforth, 2007; McBride \& Derevensky, 2009; Hawi, 2012; Rokach, 2004; Qualter \& Munn, 2002; Ilhan, 2012; Agarwal \& Karahanna 2000; Webster \& Hackley, 1997; Chen, 2000; Leong, 2011; Lin, 2009; Saade \& Bahli, 2005; Zhang et all., 2006). It is theoretically known that internet addiction, loneliness and cognitive absorption reciprocally affect each other. However, no previous research has been found which statistically confirms the accuracy of the theoretical knowledge related to all three of these themes. In this research internet addiction has been dealt with as predictor and predicted variable, this situation has been analyzed from the perspectives of loneliness and cognitive absorption and a tangible model has been put forth. Besides, in this research an answer has been sought for the question of "Does internet addiction more strongly predict loneliness or does loneliness more strongly predict internet addiction?".

\section{Theoretical Framework}

\section{Internet Addiction}

Generally speaking technology addiction can be defined as users' psychological states related to their maladaptive dependency to information technology $(\mathrm{Xu}$, et al., 2012). Within the scope of technology addiction are countless information technologies such as online games (Charlton \& Danforth, 2007), mobile e-mails (Turel \& Serenko, 2010), online gambling (McBride \& Derevensky, 2009) and social networking systems (Hawi, 2012) etc (Xu, 2012). Due to its showing similar symptoms these addiction fields can be generalized under the heading of internet addiction. As a matter of fact Chou et al., (2005) describe the internet addiction as one of the negativities that the technology causes. Some behaviors and life styles are accepted as a problem like internet addiction behavior or direct or indirect cause of disease. The concerns related to probable health risks towards internet and other new information technologies have been increasingly spreading out every day (Jiang \& Leung, 2012). These concerns have been 
causing increase in curiosity about what exactly internet addiction is and how it develops.

Internet addiction is a concept which states internet's out of control and harmful use (Sahin \& Korkmaz, 2011). Nevertheless, despite ongoing intense discussions in the literature, there is no agreed upon standard definition of internet addiction as yet (Chou et all., 2005). While some researchers prefer using " problem internet usage" instead of concept of "internet addiction" (Yellowlees \& Marks, 2007; Douglas et al., 2008), some others state that this situation is a type of addiction like substance addiction therefore the concept of "internet addiction" should be used (Beard, 2005; Davis et al., 2002). This discussion in the literature also shows that the questions of "whether internet addiction is a disease" or "what type of disease it is" currently are intensely being discussed (Jiang \& Leung, 2012). As a matter of fact, in Diagnostic and Statistical Manual of Mental Disorders (DSM IV) Arisoy (2009) and Jiang and Leung (2012) have been stating that internet addiction is not defined as a disease as yet. However, Ozturk et al. (2007) claim that the closest disease to internet addiction is pathological gambling. In a study conducted by Greenfield (1999), in similar vein it is stated that the closest disorder to internet addiction which does not involve abuse of any substance is "pathological gambling" which ranks under impulse control disorder heading in DSM IV. However, in recent years acceptances that internet addiction is a psychological disease have started to be encountered. For example in 2008 internet addiction has been approved as a psychological disease by Chinese Ministry of Health and its diagnosis criteria have been defined (Jiang \& Leung, 2012).

In media it is possible to run across much dramatic news that is thought to be caused by internet addiction. In a study performed by Jiang and Leung (2012) a youngster who killed his uncle to be able to play online gambling, a young man who met with his online girlfriend in real life and fell into depression and committed suicide after seeing that she was actually an old housewife, two people who killed each other to steal the virtual objects in a game, are presented as examples of these tragedies. Because of these potential dangers internet addiction has become an important concern for parents, educators, sociologists, psychiatrists, psychologists and others (Chou \& Hsiao, 2000). Many careful parents have been trying to prevent their children from extreme or problem internet use or prevent them from staying long hours late at nights in front of internet (Hawi, 2012). When one thinks about the psychological, social, economic, cultural and other educational losses caused by internet addiction it is an obligation to determine this situation and conduct more detailed studies on this addiction type (Sahin \& Korkmaz, 2011; Turel \& Serenko, 2010; Xu, 2012).

\section{Loneliness}

In literature loneliness is generally defined as an unwanted experience which is dealt with concepts like sadness, anger, fear and concern (Russell, Peplau \& Cutrona, 1980; Ditomasso \& Spinner, 1997). Peplau and Perlman (1982) define loneliness as unpleasant subjective psychological situation that is formed as a result of inconsistency between individual's existing social relation and the social relation he desires. Irrespective of religious belief, ethnic origin, socioeconomic level, gender and age everyone can define bitter taste of loneliness he has encountered in at least one part of his own life (Rokach, 2004). However, contrary to what is known, loneliness emerges among young adults and adolescents more than old people Jones \& Carver, 1991; Ostrov \& Offer, 1980; Hartog, 1980; Rubenstein \& Shaver, 1982). In spite of that loneliness by its nature is a subjective state which can be assessed with respect to individual's expectation from interpersonal relations and the personal satisfaction he gets from his relations (Ilhan, 2012). While man might not get the feeling of loneliness when he is alone, he might perceive himself lonely when he is in crowds (Qualter \& Munn, 2002). Weiss (1973) has been expressing the loneliness as a feeling that emerges as a result of deficiency of social relations the person has or absence of characteristics like intimacy, sincerity and sharing of feelings in his social relations and he has been seeing loneliness as a problem related to quality of interpersonal relations rather than quantity of them. Additionally Weiss ( 1987) has dealt with loneliness at two theoretical dimensions as emotional and social and he has analyzed family and private friendship relations in emotional dimension and friendship relations in social environments in social dimension. Russel et al. (1980) however, have claimed that loneliness had one dimension and defined loneliness as a universal phenomenon which is experienced at different levels and intensities and which affects all aspects of life (social, psychological, cultural etc.) (Cecen, 2008).

The studies conducted in recent years have provided important contributions in putting forth the causes and results of loneliness. These studies have been concentrating on such factors as deficiencies in communications and social skills, negative expectations, extreme cognitive loadings, shyness, affiliation without trust, inadequate social support perception and unconformity in family structure and almost all of these factors are being shown as the cause of loneliness (Ilhan, 2012). The loneliness feelings that individuals experience, depending on its dimension and strength, can give way to negative situations like depression, hearth diseases, hypertension, suicide attempts, substance use, low life satisfaction (Alpass \& Neville, 
2003; Cacioppo et.al., 2006; Hawkley et all.,, 2003; Wenz, 1977; McWhirter, 1990; Momtaz et all. 2012).

\section{Cognitive Absorption}

Agarwal and Karahanna (2000) define cognitive absorption as a deep addiction which stems from experiences related to information technologies. It is possible to say that at the foundation of cognitive absorption are the integrated experiences that individuals have gained in regards to technology. Integrative approach focuses on such structures as satisfaction level of individuals during their interaction with technology and their perception in this process. These types of structures are significant predictors of technology use and acceptance level of individuals. Integrative experiences can be explained by cognitive absorption concept. Cognitive absorption can be expressed as a different form of internal motivation (Saade \& Bahli, 2005).

One of the other important dynamics of cognitive absorption is deep addiction. Deep addiction is explained by five basic phenomena as time, curiosity, pleasure, control and focus of interest. According to Agarwal and Karahanna (2000) time expresses the state that while individual interacts with technology he cannot realize how the time passes by; curiosity expresses the state that individual gets curious when he interacts with technology; focus of interest expresses the state that when interacting with technology he gives his entire attention to the thing being done; pleasure expresses the state that he gets pleasure from interacting with technology; and control expresses the state that in the interaction process with technology individual feels that he is in control.

Cognitive absorption can be explained by three fundamental key concepts. These are "State of Flow", "Trait of Absorption" and "Notion Cognitive Engagement" (Agarwal \& Karahanna, 2000). Flow is the state when the individual does not pay attention to other stimulus except the activity he is interested at that moment (Csikszentmihalyi, 1990); absorption expresses the state when all attention of the individual is occupied by one of his objects (Tellegen \& Atkinson 1974); and cognitive engagement however expresses the state when the individual loses the track of time and directs his attention entirely to the thing he is doing (Webster \& Ho, 1997; Webster \& Hackley, 1997).

It is possible to come across many researches in the literature about positive contribution of cognitive absorption state to perceptions and beliefs of individuals regarding benefiting from information technologies as well as to the ease of use of these technologies (Webster \& Hackley, 1997; Chen, 2000; Leong, 2011; Lin, 2009; Saade \& Bahli, 2005; Zhang et. al. 2006). As a matter of fact Saade and Bahli (2005) emphasize that cognitive absorption is a significant predictor of technology use and acceptance levels of individuals.

\section{Research Hypotheses}

Based upon the theoretical foundation explained above, the hypotheses that have been developed to test the effects of internet addiction, loneliness and cognitive absorption on each other and rate of explaining each other have been presented below.

H1: Loneliness level of candidate teachers affects internet addiction in positive way and significantly

H2: Loneliness and cognitive absorption levels of candidate teachers together significantly explain internet addiction

H3: Internet addiction of candidate teachers affects loneliness level in positive way and significantly.

H4: Internet addiction and cognitive absorption level of candidate teachers together explain loneliness level significantly.

\section{METHOD}

\section{Research Model}

Because the aim of the investigation is the effect of internet addiction, cognitive absorption and loneliness perceived by teacher candidates, relational descriptive model in descriptive research model is used in this investigation, since descriptive research model is a suitable model for investigations to describe the present situation as it stands (Karasar, 2012). Descriptive research models are divided into two; general descriptive research and sample descriptive research. Relational descriptive model is a model in general descriptive research. Since relational descriptive models are used for research models aiming to determine the change or the degree of the change among two or more variables in general descriptive research group, it is suitable for these type of researches (Karasar, 2012). Relational descriptive model was applied to this research according to structural equation model. Structural equation model is explained $\mathrm{n}$ data analysis section below.

\section{Participants}

Participant group of the research has been constituted by 338 teacher candidates studying at third and fourth class level in spring semester of 2010-1011 academic year at Firat University Education Faculty. Because structural equation models are based on significance of the difference in covariance matrix and tests that are sensitive to number of participants, when these types of models are constructed number of participants need to be greater than 200 (Bayram, 
2010). Because participants of the research have been constituted by 338 people this number is suitable for the purpose of the research and statistical analysis. Demographic characteristics of the participants are as follows: From gender perspective, $52.7 \%$ of the participants are female $(\mathrm{f}=178) \quad 47.3 \%$ are male $(\mathrm{f}=160)$. From the perspective of studied class level $32 \%$ of participants have been studying at third grade $(\mathrm{f}=108), 68 \%$ have been studying at fourth grade $(\mathrm{f}=230)$. From the perspective of studied program type $21.6 \%$ of the participants ( $\mathrm{f}=73$ ) study science and technology teaching, $21.3 \% \quad(\mathrm{f}=72)$ study classroom teaching, $15.4 \%$ ( $\mathrm{f}=52)$ study education of religion and ethics teaching , $14.5 \%(\mathrm{f}=49)$ study Turkish language teaching, $11.8 \%(\mathrm{f}=40)$ study history teaching, $8 \%$ $(\mathrm{f}=27)$ study primary education mathematics teaching, $7.4 \%(\mathrm{f}=25)$ study social studies teaching.

\section{Data Gathering Instruments and Confirmatory Factor Analysis}

Loneliness Scale: In order to measure loneliness levels of individuals the scale which was developed by Russell, Peplau and Ferguson (1978) has been used. Scale has been adapted to Turkish by many researchers and in this study research's version which was adapted to Turkish by Demir (1989) and used in Yildirim's (2007) study has been used. In the scale that was made up of a single factor there are total of 20 items as ten positive and ten negative. Reliability coefficient of the measurement device has been calculated by Cronbach Alpha method and reliability coefficient of the test has been found to be 96 . In the Loneliness Scale four point likert type items were placed and each item has been assessed by four point grading as "I experience frequently" (4), "I sometime experience" (3), "I seldom experience"(2), "I never experience" (1).

On the data obtained from this study reliability coefficient of measurement instrument has been calculated by Cronbach Alpha method and reliability coefficient of the test has been found to be .78 . On the other hand, as a result of exploratory factor analysis however, factor load values of items ranking among the scale have been determined to be between .71 and .43 and all the coefficients have been found to be within acceptable limits. To illustrate the items taking part in this scale these two items have been given as example My interests and ideas are not shared by people around me (Y8). There are people who really understand me (Y16). Additionally, confirmatory factor analysis diagram of the scale is presented in Figure 1.

As a result of confirmatory factor analysis, when the assessment of normality is taken into account, it has been seen that from the perspective of multivariate (Mardia) values critical ratio (c.r) is 24.450 . However because there was no item whose critical ratio value was exceeding +5 and -5 , an improvement has been made by taking into account the other modification index values and four items have been excluded from the assessment in this regard. In this case when the results of confirmatory factor analysis of "Loneliness Scale" which was made up of 16 items are taken into account fitness values have been found to be as follows: RMSEA $=.053, \quad$ SRMR $=.043 ; \quad$ CMIN/DF $\left(\mathrm{X}^{2} / \mathrm{sd}\right)=2.772 ; \mathrm{GFI}=.963$; $\mathrm{CFI}=.956 ; \mathrm{AGFI}=.890$ and $\mathrm{NFI}=.910$ This result shows that fit values of the model are acceptable and at desirable level.

Cognitive Absorption Scale: The Cognitive Absorption scale which was developed by Agarwal and Karahanna (2000) has been adapted to Turkish language by Usluel and Vural. Cognitive absorption scale is made up of 17 items and four factors as time, curiosity, focus of interest and pleasure. Factor load values of items taking part in the scale have been changing between .864 and .586 . Cronbach Alpha reliability coefficient of the scale is .88 at time dimension, is .90 at curiosity dimension, is .82 at focus of interest dimension and is .90 at pleasure dimension and it is .92 for the entire scale. Scale items have been assessed by five point grading stated as "I completely agree" (5), "I agree" (4), "I partly agree" (3) , "I don't agree" (2) and "I definitely disagree" (1). Reliability coefficient Cronbach Alpha value of this study is .90 at time dimension, is .80 at curiosity dimension, is .71 at focus of interest dimension, is .87 at pleasure dimension and it is .90 for the entire scale. Factor load values of items taking part in the scale have been determined to be between .795 and .437 and all coefficients have been found to be within acceptable limits. One example has been provided for the items taking part in each of the six sub dimensions. When using Web I sometime lose track of time (B3). Using Web increases my curiosity (B6). When I am on Web I can easily collect my attention (B11). Using Web is pleasure for me on its own (B17). Additionally confirmatory factor analysis diagram of the scale has been presented in Figure 2. 
As a result of confirmatory factor analysis, when the ssessment of normality is taken into account, it has been seen that from perspective of the multivariate (Mardia) values critical ratio (c.r) is 38.162 However, because there is no item whose critical ratio value exceeds +5 and -5 an improvement has been made by taking other modification index values into account. To this end, one item has been excluded from the analysis and error rates of four items have been combined. In such a case when the confirmatory factor analysis results of "Cognitive Absorption Scale" which is made up of 16 items are taken into account fit values have been found as follows : $\quad$ RMSEA $=.072 ; \quad$ SRMR $=.0526 ; \quad \mathrm{CMIN} / \mathrm{DF}$ $\left(\mathrm{X}^{2} / \mathrm{sd}\right)=2.737$; GFI $=.916$; $\mathrm{CFI}=.952$; $\mathrm{AGFI}=.880$ and

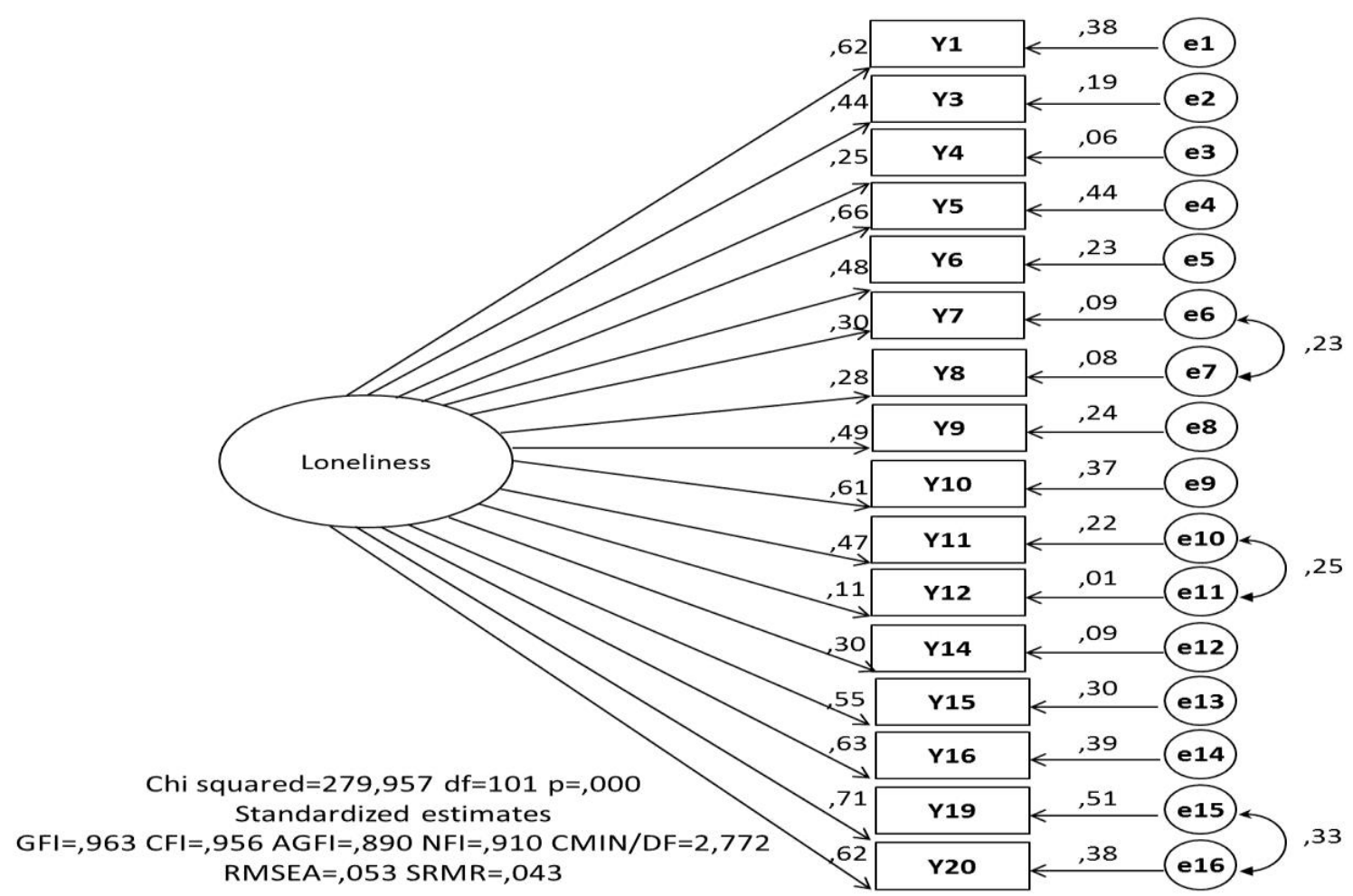

Figure 1. Loneliness Scale Confirmatory Factor Analysis Diagram

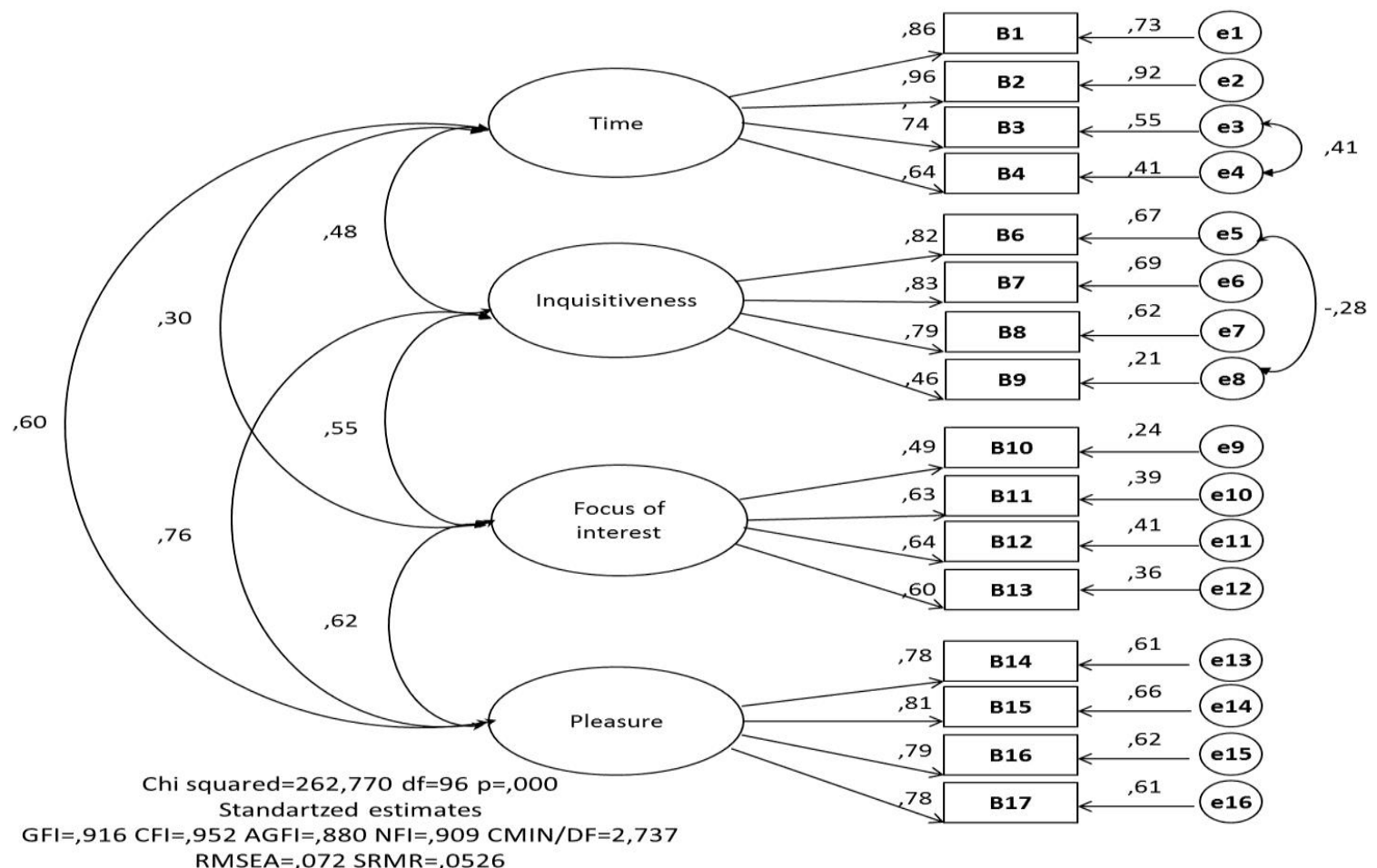

Figure 2. Cognitive Absorption Scale Confirmatory Factor Analysis Diagram 
NFI $=.909$. This results shows that fit values of the model are acceptable and at desired level.

Internet Addiction Scale: The internet addiction scale which was developed by Gunuc (2009) consists of 35 items and four dimensions as deprivation, difficulty in control, deterioration in functionality and social isolation. Factor load values of the scale vary between .702 and .389. Cronbach Alpha reliability coefficient of the scale is .877 at deprivation dimension, is .855 at difficulty in control dimension, is .827 at deterioration in functionality dimension, is .791 at social isolation dimension and it is .944 for the entire scale.

The agreement degrees for the items of the scale which was prepared in 5 point likert type are in the form of "I completely agree" (5), "I agree" (4), " I partly agree" (3), "I don't agree" (2), "I definitely don't agree" (1). As a result of the analyses made on the data obtained in this study factor load values of the scale are in the range of .811 and .485 all the coefficients are within the acceptable limits. Cronbach Alpha reliability coefficient of the scale is .888 at deprivation dimension, is .870 at difficulty in control dimension, is .876 at deterioration in functionality dimension, is .898 at social isolation dimension and it is .953 for the entire scale. One example for the items taking part in each of the six sub dimension of this study has been given. When I don't use internet I feel myself tense/ restless (I1). I have difficulty in restricting or controlling my internet usage (I12). Because of my internet usage my interest for other activities (sports, movies, reading books etc) diminishes (I24). I prefer the friendships I make in internet environment to the friends in real life (I30).
Additionally, confirmatory factor analysis of the scale has been presented in Figure 3.

As a result of confirmatory factor analysis, when the assessment of normality is taken into account, it has been seen that from the perspective of multivariate ( Mardia) values critical ratio rate (c.r) is 114.322 . Therefore seven items whose critical ratios were greater than 10 have not been analyzed in the next step and error rates of ten items have been combined. In such a case, when the confirmatory factor analysis results of "Internet Addiction Scale" which is made up of 28 items are taken into account fit values have been found as follows: RMSE $A=.076 ; S R M R=.0582 ; C M I N / D F$ $\left(\mathrm{X}^{2} / s d\right)=2.737$; $G F I=.915 ; \mathrm{CFI}=.951 ; A G F I=.861$ and NFI=.957 This result shows that fit value of the model is acceptable and at desired level.

\section{Data Gathering Process}

In line with research objectives, for the use of scales permissions have been obtained from scale owners and in the process of application of scales participants have joined voluntarily. Participants have been told about objectives and application ways of the scales. Application times of the scales which have been applied between 09 - 30 May 2011 have taken average of 25 minutes per person.

\section{Analysis of Data}

Obtained data firstly have been entered SPSS 17.0

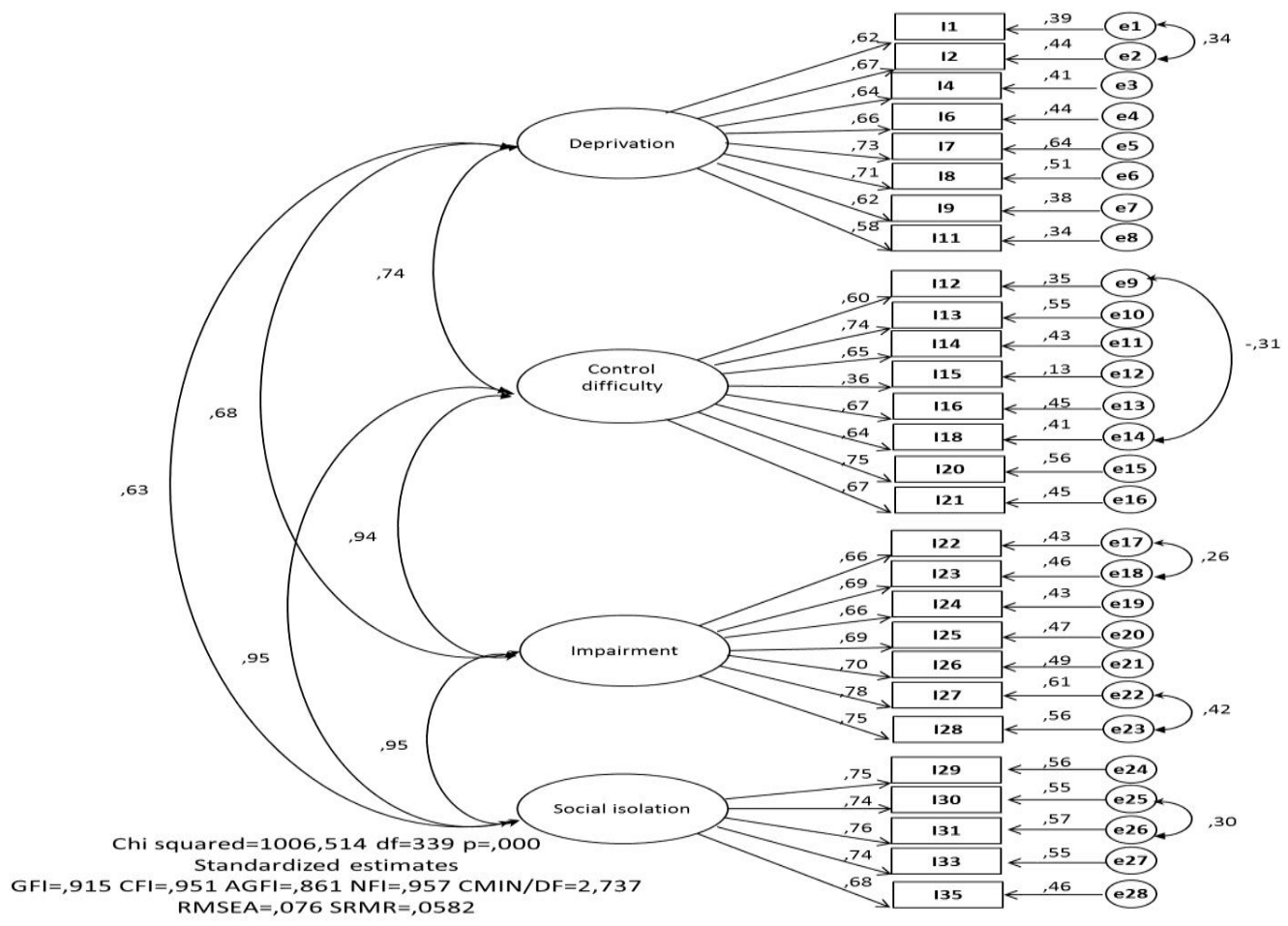

Figure 3. Internet Addiction Scale Confirmatory Factor Analysis Diagram 
package program and demographic characteristics of articipants as well as exploratory factor analysis of scales have been analyzed by this program. For the exploratory factor analyses of the scales SPSS 17.0 has been used and for confirmatory factor analysis and structural equation model AMOS 17.0 data analysis program has been used. Confirmatory factor analysis is a method which is mostly applied after exploratory factor analysis studies. At the same time this analysis takes into account contributions of all probable relations to the model and modification indices which were not thought previously by the researcher but which become evident when the data set in question is taken into account (Simsek, 2007). Confirmatory factory analysis puts forward more

$-25$

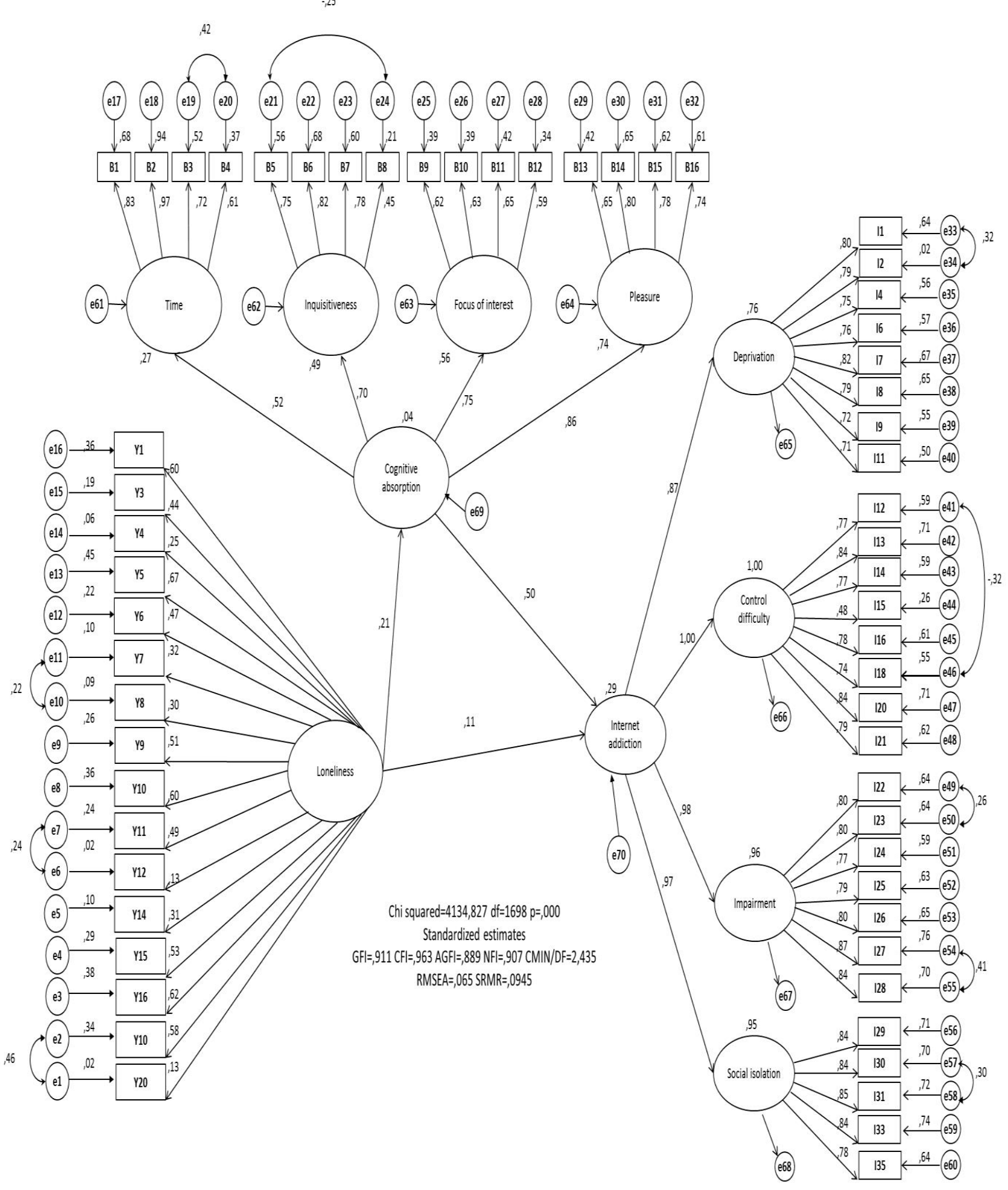

Figure 4. Equation Model Constructed Related to H1 and H2 Hypotheses 
realistic statistical results (Kline, 2005). Besides, in line with hypotheses of the research a structural equation model has been formed. Structural equation model is in use in social sciences since the end of 1980s. Because of such reasons as it takes into account the measurement errors related to observed variables and direct and indirect effects of variables in the model, it allows researchers to develop, forecast and test multi variable complex models structural equation models are being used in scientific studies widely (Bayram, 2010).

Above mentioned characteristics also set forth the reasoning behind using confirmatory factor analysis and structural equation model in this study. In confirmatory factor analysis while forecasting model parameters maximum likelihood method has been used. In assessing model goodness of fit root mean square error of approximation (RMSEA), standardized root mean square residual (SRMR), goodness of fit index (GFI), comparative fit index (CFI), adjusted goodness of fit index (AGFI), normed fit index (NFI) and chi-square / degrees of freedom $\left(\mathrm{X}^{2} / \mathrm{sd}=\mathrm{CMIN} / \mathrm{DF}\right)$ and level of significance (p) fit indices have been taken into account. The fact that RMSEA value is between 0-0.08; SRMR values is between 0-0.10; GFI value is between 0.90 1.00; CFI value is between 0.90-1.00; AGFI value is between 0.85-1.00; NFI value is between .90-1.00; $\mathrm{X}^{2} / \mathrm{sd}(\mathrm{CMIN} / \mathrm{DF})$ value is between $0-3 ; \mathrm{p}$ value is between 0.01-0.05 shows good fit indices. (Bayram, 2010; Byrne, 2001; Joreskog \& Sorbom, 1993; Kline, 2005; Schermelleh-Engel \& Moosbrugger, 2003; Reisinger \& Mavondo, 2006; Simsek, 2007). In exploratory and confirmatory factor analyses lower limit of factor loads of items has been accepted to be 0.30 . If there are few items in a scale prepared in social science field the limit value for factor load value can be decreased up to 0.30 . Additionally, if an item whose factor value is below 0.30 has significant effect on scope validity of the scale then in such a case analyses can be made without taking out the item in question (Buyukozturk, 2007). On the other hand, in assessment of normality for confirmatory factor analysis and structural equation model critical ratio's being below 10 has been used as a base. According to Kline (2005) in a sense critical ratio is normalized forecast of multivariate kurtosis, which means that it is $\mathrm{z}$ value. Absolute value of critical ratio's being greater than 10 sets forth that there is a problem with kurtosis value of the distribution.

\section{RESULTS}

As a result of the research two models that show the extent of effect of internet addiction, loneliness and cognitive absorption latent variables on each other and their explanation rate of each other have been put forth. When these models were being constructed, testing of hypotheses of the study has been taken into account. To this end, the structural equation model constructed related to first and second hypotheses of the research is presented in Figure 4.

Presented in Figure 4, the fit values of the model that was constructed related to first and second hypotheses of the research have been obtained as follows: $\quad \mathrm{RMSEA}=.065 ; \quad \mathrm{SRMR}=.0945$; $\mathrm{CMIN} \backslash \mathrm{DF}=2,435$; GFI=.911; $\mathrm{CFI}=.963$; $\mathrm{AGFI}=.889$; $\mathrm{NFI}=.907 ; \quad$ Chi squared $=4144,827 ; \quad \mathrm{df}=1698$ and $\mathrm{p}=.000$. This results shows that fit values of the model are acceptable and at desired level.

Loneliness scale has 16 observed variables. Among the observed variables the one with the highest effect coefficient is $\mathrm{Y} 5$ and the ones with lowest effect coefficient are Y12 and Y20. Effect coefficients of observed variables taking part in this scale vary between .67 and .13

Cognitive absorption scale has four latent variables as time, curiosity, interest and pleasure and 16 observed variables. Effect coefficients of latent variables taking part in this scale vary between .86 and .52 .

Internet addiction scale has four latent variables as deprivation, difficulty in control, deterioration in functionality and social isolation and 28 observed variables. Effect coefficients of latent variables taking part in this scale vary between 1.00 and .87

As it can be seen from the model that is presented in Figure 4 and that has been obtained as a result of the research, it has been determined that loneliness level affects internet addiction significantly at .11 level and in positive direction. This result shows the accuracy of the H1 hypothesis of "Loneliness level of candidate teachers affects internet addiction in positive way and significantly". On the other hand, loneliness and cognitive absorption together have been explaining the internet addiction at the rate of $29 \%$. In other words, it can be said that change taking place in internet addiction is $29 \%$ dependent on loneliness and cognitive absorption. This results confirms the $\mathrm{H} 2$ hypothesis of "Loneliness and cognitive absorption levels of candidate teachers together significantly explain internet addiction The structural equation model constructed related to third and fourth hypotheses of the research is presented in Figure 5.

Presented in Figure 5, the fit values of the model that was constructed related to third and fourth hypotheses of the research have been obtained as follows: $\quad \mathrm{RMSEA}=.068 ; \quad \mathrm{SRMR}=.0985$; $\mathrm{CMIN} \backslash \mathrm{DF}=2,548 ; \mathrm{GFI}=.910 ; \mathrm{CFI}=.944 ; \mathrm{AGFI}=.888$; NFI $=.912 ; \quad$ Chi squared $=4327,340 ; \quad \mathrm{df}=1698$ and $\mathrm{p}=.000$. This results shows that fit values of the model are acceptable and at desired level.

Loneliness scale has 16 observed variables. Among the observed variables the ones with the highest effect coefficient are Y19 and Y20 and the one with the lowest 
effect coefficient is Y12. Effect coefficients of observed variables taking part in this scale vary between .91 and .17

Cognitive absorption scale has four latent variables as time, curiosity, interest and pleasure and 16 observed variables. Effect coefficients of observed variables taking part in this scale vary between .94 and .69

Internet addiction scale has four latent variables as deprivation, difficulty in control, deterioration in functionality and social isolation and 28 observed

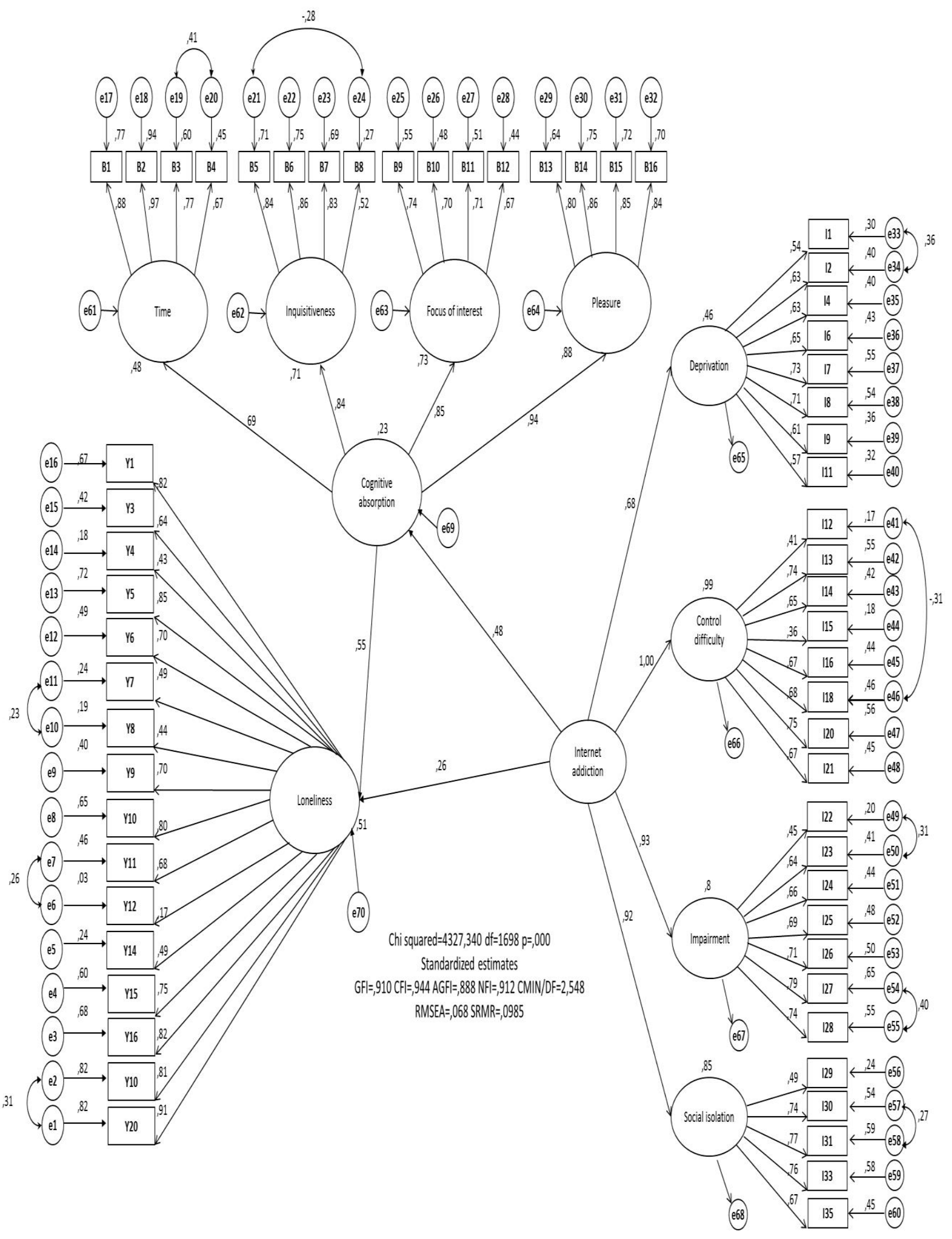

Figure 5. Equation Model Constructed Related to H3 and H4 Hypotheses 
variables. Effect coefficients of latent variables taking part in this scale vary between 1.00 and .68

As it can be seen from the model that is presented in Figure 5 and that has been obtained as a result of the research, it has been determined that internet addiction affects loneliness level significantly at .26 level and in positive direction. This result shows the accuracy of the H3 hypothesis of "Internet addiction of candidate teachers affects loneliness level in positive way and significantly". On the other hand, internet addiction and cognitive absorption together have been explaining the loneliness level at the rate of $51 \%$. In other words, it can be said that change taking place in loneliness level is $51 \%$ dependent on internet addiction and cognitive absorption. This result confirms the $\mathrm{H} 4$ hypothesis of "Internet addiction and cognitive absorption level of candidate teachers together explain loneliness level significantly".

\section{CONCLUSION AND DISCUSSION}

What kind of relation there is between internet addiction and loneliness and which of these relations is dominant is mentioned in first and third hypotheses. It was determined that loneliness positively and meaningfully affects internet addiction at .11 level, and internet addiction positively and meaningfully affects loneliness at .26 level. And this situation has been putting forth that as the loneliness level of individuals increases they can become internet addicted and likewise, internet addicted individuals gradually start to feel themselves alone. When the loneliness feeling is dealt with as a psychological state, that this feeling can cause internet addiction which is accepted as one of the diseases of our times or that it can be a result of internet addiction have been emphasized by Orzack (1999), Young (1998) and Odaci and Kalkan (2010). That the internet usage which reached the stage of addiction makes people lonely and as their loneliness increases their internet addiction intensifies is frequently emphasized similarly in literature (Morahan-Martin, 1999; Amichai-Hamburger et al. 2002). In other words, as the loneliness levels of candidate teachers who are the target group of this research increase in a sense they start to see internet as a friend to themselves. As a matter of fact, it can be said that being the young adults in the first place this finding is valid for all age groups rather than being relevant only to candidate teachers. The disappointments of particularly young adults, who might be candidate teacher as well, that they experienced in physical and social environments and failures and bad experiences they had in interpersonal relations can in a sense direct them towards the virtual world out of hand and as a natural result can turn them into a internet addicted individual (Chou \& Hsiao, 2000; Wainer et al., 2008; Orchard and Fullwood, 2010; Cao \&
Su, 2006). In such a case it can be said that individuals can even perceive the virtual friendships and hostilities as real and this situation can make the individual aggressive, that depending on its intensity it should be treated (Bernardon et.al., 2011; Ozturk et.al., 2007) and that as a result of all of these, intense feeling of loneliness emerges in the individual. As a result it can be said that both the state of internet addiction and loneliness feeling are in a two-ways strong cause-effect relationship with each other. When thought about it within this framework, it can be said that in order to facilitate benefiting of information age individuals in general and candidate teachers in particular from information technologies in an adequate and healthy way it is not enough for them to be only literate but it is necessary to take precautions to allow them to socialize in real environments in a right way. Thus, according to the results reached in this research, it can be said that probability for a candidate teacher who has a healthy social environment without having the feeling of loneliness in real environments to become internet addicted is low.

The level of explaining loneliness and internet addiction each other together with cognitive absorption is mentioned in second and fourth hypotheses. It has been determined that loneliness and cognitive absorption explain internet addiction at $\% 26$, and internet addiction and cognitive absorption explain loneliness at $\% 51$. According to this situation it can be asserted that internet addiction explains loneliness better. In another words as their internet addiction levels and cognitive absorption levels increase they get the feeling of loneliness more intensely. The finding obtained here has relation with the concept of "deep dependency" which has been emphasized by Agarwal and Karahanna (2000) and which is considered important when explaining the feeling of cognitive absorption and which has five elements as time, curiosity, pleasure, control and interest. In other words, if a candidate teacher does not realize how the time passes by when he is on internet, if his curiosity is constantly alive in this process, if he does not have problem of concentrating his attention to the place he has been navigating on internet environment, if he has been getting pleasure from all these processes he has been experiencing and finally if he feels that he is in control then cognitive absorption level of this individual is high. When the internet addiction is added on top of this, the probability of individual's having the feeling of loneliness increases. On the other hand cognitive absorption and loneliness feeling however can turn the individual into an internet addicted individual. Here the point to take into consideration is that cognitive absorption should not be dealt with as a negative concept like internet addiction. As it was explained with its five elements, cognitive absorption is a state which 
keeps alive internal motivation of individual and where control is never lost in technology use. However, this situation is not valid for internet addiction and it can put the individual into inextricable and very difficult positions and can detach him completely from the real life. However, being a positive behavior the cognitive absorption can turn into a negative addiction instrument when problem internet use comes into question. Thusly, result of this research conducted is supportive of this situation. However, lack of adequate number of evidence towards joint effect of these concepts in literature has not allowed for further discussion of this situation.

On the other hand together with cognitive absorption, which one of loneliness or internet addiction is the reason and which one is the result can vary with respect to cultures. As a matter of fact, despite the fact that loneliness and internet addiction are tackled as universal concepts in literature, dealing with these concepts separate from cultural factors and physical environment is almost impossible. Possible difference between the culture a person belongs to and the culture he actually is in as well as different social pressure, direction instruments, physical and characteristic features in those cultures show that it would not be that correct to analyze those tackled concepts by isolating them from the culture. Similarly, researchers like Goodwin, Cook, \& Yung, (2001), Cao \& Su, (2007), Wood, (2007), Bluigte, (1991), Rokach and Bacanli, (2001), Rokach and Neto, (2000), Ditommaso et al. (2005) have emphasized that loneliness being in the first place in regards to absorption and dependency culture and cultural factors are important determinants and these feelings can surface in different ways. As a result, it is possible to say that when the cause effect relation between these three variables is taken into account both of the second and the fourth hypotheses are important and depending on the cultural differences one may one step come forward than the other.

\section{REFERENCES}

Agarwal, R. \& Karahanna, E. (2000). Time flies when you're having fun: Cognitive absorption and beliefs about information technology usage, MIS Quarterly, 24(4), 665-694.

Alpass, F. M., \& Neville, S. (2003). Loneliness, health and depression in older males, Aging \& Mental Health, 7, 212-216.

Amichai-Hamburger, Y., \& Ben-Artzi, E. (2003). Loneliness and Internet use, Computers in Human Behavior, 19(1), 7180.

Amichai-Hamburger, Y., Wainapel, G., \& Fox, S. (2002). “On the Internet no one knows I'm an introvert":Extroversion, neuroticism, and Internet interaction, CyberPsychology \& Behavior, 5, 125-128.

Arisoy, O. (2009). Internet addiction and its treatment, Current Approaches In Psychiatry, 1(1), 55-67.
Bayram, N. (2010). Yapısal eșitlik modellemesine giriș, AMOS uygulamalar, (Introduction to structural equation modeling, AMOS applications), Bursa, Ezgi Pub.

Beard, K.W. (2005). Internet addiction: A review of current assessment techniques and potential assessment questions, CyberPsychology and Behavior, 8(1), 7-14.

Bernardon, S., Babb, K. A., Hakim-Larson, J., \& Gragg, M. (2011). Loneliness, attachment, and the perception and use of social support in university students, Canadian Journal of Behavioural Science, 43(1), 40-51.

Buyukozturk, S.. (2007). Sosyal bilimler için veri analizi el kitabi (Handbook of data analysis for social sciences), Ankara, Pegem A Pub.

Byrne, B. M. (2001). Structural equation modeling with AMOS, Mahwah, N. J.: Lawrence Erlbaum Associates.

Cacioppo, J. T., Hughes, M. E., Waite, L, J., Hawkley, L. C., \& Thisted, R. A. (2006). Loneliness as a specific risk factor for depressive symptoms: Cross-Sectional and longitudinal analyses, Psychology and Aging, 21(1), 140151.

Cao, F., \& Su, L. (2006). Internet addiction among Chinese adolescents: Prevalence and psychological features, Child: Care, Health and Development, 33, 275-281.

Charlton, J. P., \& Danforth, I. D. W. (2007) Distinguishing addiction and high engagement in the context of online game playing, Computers in Human Behavior 23(3), 15311548.

Chen, H. (2000). Exploring Web users' on-line optimal flow experiences, Dissertation Abstracts International, 61(7), 2499. (UMI No. 9977961)

Chou, C. M., \& Hsiao, C. (2000). Internet addiction, usage, gratification, and pleasure experience: The Taiwan college students' case, Computers \& Education, 35(1), 6580 .

Chou, C., Condron, L., \& Belland, J. C. (2005). A review of the research on internet addiction, Educational Psychology Review, 17(4), 363-388

Coget, J-F., Yamauchi, Y., \& Suman, M. (2002). The internet, social networks and loneliness, IT\&Society, 1(1), 180201.

Csikszentmihalyi, M. (1990). Flow: The psychology of optimal experiences. New York: Harper and Row.

Çeçen, A. R. (2008). University students' loneliness and perceived social support levels according to gender and perceived parents attitudes, Journal of Turkish Education Science, 6(3), 415-431.

Davis, R., Gordon Flett, L.G., \& Besser, A. (2002). Validation of a new scale for measuring problematic Internet use: Implications for pre-employment screening, CyberPsychology \& Behavior, 5(4). 331-345.

Demir, A. (1989), UCLA loneliness scale: A validity and reliability study, Turkish Journal of Psychology, 7(23), 14-18.

DiTommaso, E., \& Spinner, B. (1997). Social and emotional loneliness: A re-examination of Weiss' typology of loneliness, Personality and Individual Differences, 22(3), 417427.

Ditommaso,E., Brannen, C., \& Burgess, M. (2005). The universality of relationship characteristics: A crosscultural comparison of different types of attachment and loneliness in Canadian and visiting Chinese students, Social Behavior and Personality, 33(1), 57-68 
Douglas, A. C. ., Mills, J. M. ., Niang, M. , Stepchenkova, S., Byun, S., Ruffini, S et al. (2008). Internet addiction: Meta-synthesis of qualitative research for the decade 1996-2006, Computers in Human Behavior, 24(6), 3027 3044.

Goodwin. R., Cook. O., \& Yung. Y. (2001). Loneliness and life satisfaction in three cultural groups, Personal Relationships, 8, 225-230.

Greenfield, D. N. (1999). Psychological characters of compulsive internet use: a preliminary analysis, Cyberpsychol Behav, 2: 403-412

Gunuc, S. (2009). Development of internet addiction scale and scrutinising the relations between the internet addiction and some demographic variables, Unpublished Master's Thesis, Yüzüncü Yıl University, Institute of Social Sciences, Turkey, Number of Thesis: 234300

Hannafin, M. J., \& Peck, K. L. (1988) The design, development, and evaluation of instructional software, New York, Macmillan Publishing Company.

Hartog, J. (1980). The anlage and ontogeny of loneliness. J. Hartog; J. R Audy \& Y. A. Cohen (Eds.), The anotomy of loneliness (s.13-33). New York: International Universities Press.

Hawi, N. S., (2012).Internet addiction among adolescents in Lebanon, Computers in Human Behavior, 28(3), 1044 1053.

Hawkley, L. C., Burleson, M. H., Berntson, G. G., \& Cacioppo, J. T. (2003). Loneliness in everyday life: Cardiovascular activity, psychosocial context, and health behaviors, Journal of Personality and Social Psychology, 85, 105-120.

İlhan, T. (In press, 2012). Üniversite öğrencilerinde yalnızlık: cinsiyet rolleri ve bağlanma stillerinin yalnızlığ1 yordama güçleri, Educational Sciences: Theory \& Practice.

Jiang, Q., \& Leung, L. (2012). Effects of individual differences, awareness-knowledge, and acceptance of internet addiction as a health risk on willingness to change internet habits, Social Science Computer Review, 30(2), 170-183.

Jones, W. H., \& Carver, M. D. (1991). Adjustment and coping implications of loneliness, R. Snyder ve D.R. Forsyth (Eds.), Handbook of social and clinical psychology: The healthy perspective (395-415) New York: Pergamon Press.

Joreskog, K. G., \& D. Sorbom (1993). LISREL 8: Structural equation modeling with the SIMPLIS command language, Chicago, IL: Scientific International Software.

Karasar, N. (2012). Bilimsel araştırma yöntemi, (Scientific research methods), Ankara, Nobel Pub.

Kelleci, M. (2008).The effects of internet use, cell phones and computer games on mental health of children and adolescents, TAF Preventive Medicine Bulletin, 7(3), 253256.

Khasawneh, O. M., \& Al-Awidi, H. M. (2008). The effect of home computer use on Jordanian children: A parental perspective, J. Educational Computing Research, 39(3), 267284.

Kline, B. R. (2005). Principles and Practice of Structural Equation Modeling, New York, The Guilford Press, $2^{\text {nd }}$ ed.

Leong, P. (2011). Role of social presence and cognitive absorption in online learning environments, Distance
Education, 32(1), 5-28. Doi: $10.1080 / 01587919.2011 .565495$

Lin, H. (2009). Examination of cognitive absorption influencing the intention to use a virtual community, Behaviour and Information Technology, 28(5), 421-431.

Lisa J. Orchard, L.J., \& Fullwood, C. (2010). Current Perspectives on Personality and Internet Use, Social Science Computer Review, 28(2), 155-169.

McBride, J., \& Derevensky, J. (2009) Internet gambling behavior in a sample of online gamblers. International Journal of Mental Health and Addiction, 7(1), 149-167.

McWhirter, B. R. (1990). Loneliness:Areview of current literature, with implications for counseling and research, Journal of Counseling and Development, (68), 417-422.

Momtaz, Y.A., Hamid, A,T., Yusoff, S., Chai, S.T., Yahaya, N., \& Abdullah, S.S. (2012). Loneliness as a Risk Factor for Hypertension in Later Life, Journal of Aging and Health, 24(4), 696-710. Doi: $10.1177 / 0898264311431305$

Moody, E. J.(2001). Internet use and its relationship to loneliness, CyberPsychology \& Behavior, 4(3), 393-401.

Morahan-Martin, J. (1999). The relationship between loneliness and internet use and abuse, CyberPsychology and Behavior, 2: 431-440.

Morahan-Martina, J., \& Schumacher, P. (2000). Incidence and correlates of pathological internet use among college students, Computers in Human Behavior, 16, 13-29.

Orhan, F., \& Akkoyunlu, B. (2004). A study on the use of internet by primary school students, Hacettepe Un. Journal of Education Faculty, 26: 107-116.

Orzack, M. (1999). Computer addiction: Is it real or virtual? Harvard Mental Health Letter, 15(7), 1-8.

Ostrov, E., \& Offer, D. (1980). Loneliness and the adolescent. içinde J. Hartog, J. R Audy ve Y. A.. Cohen (Eds.), The anotomy of loneliness (s.170-185), New York: International Universities Press.

Öztürk, Ö. Odabaşığlu, G., Eraslan, D., Genç, Y., \& Kalyoncu, Ö. A. (2007). Internet addiction: Clinical aspects and treatment strategies, Journal of Dependence, 8: 36-41

Odac1, H., \& Kalkan, M. (2010). Problematic Internet use, loneliness and dating anxiety among young adult university students, Computers \& Education 55; 10911097. doi:10.1016/j.compedu.2010.05.006

Qualter, P., \& Munn, P. (2002). The separateness of social and emotional loneliness in childhood, Journal of Child Psychology and Psychiatry, 43, 233-244.

Peplau, L. A., \& Perlman, D. (1982). Perspectives on loneliness. In A. A. Peplau \& D. Perlman (Eds.), Loneliness: A sourcebook of current theory, research, and therapy (pp. 1-18). New York: Wiley-Interscience.

Reisinger, Y. \& Mavondo, F. T. (2006) Structural equation modelling: critical issues and new development, Journal of Travel and Tourism Marketing, 21(4), 41-72.

Rokach, A. (2004). Loneliness then and now: Reflections on social and emotional alienation in everyday life, Current Psychology: Developmental, Learning, Personality, Social, 23(1), 24-40.

Rokach. A., \& Bacanh. H. (2001). The experience of loneliness in Canada, Argentina, and Turkey,

Psychological Studies, 46: 77-87. 
Rokach. A.. \& Neto. F. (2000). Causes of loneliness in adolescence: A cross-cultural study, International Journal of Adolescence and Youth, 8: 65-80.

Rubenstein, C. M., \& Shaver, P. (1982). The experience of loneliness. İçinde L. A. Peplau ve D. Perlman (Eds.), Loneliness: A sourcebook of current theory, research and therapy (p.206-223). New York: Wiley.

Russell, D., Peplau, L.A., \& Cutrona, C. E. (1980). The revised UCLA Loneliness Scale: Concurrent and discriminant validity evidence, Journal of Personality and Social Psychology, 39: 472-480.

Saade, R., \& Bahli, B. (2005). The impact of cognitive absorption on perceived usefulness and perceived ease of use in on-line learning: An extension of the technology acceptance model, Information and Management, 42(2), 317-327.

Schermelleh-Engel, K. \& Moosbrugger, H. (2003). Evaluating the fit of structural equation models: tests of significance and descriptive goodness-of-fit measures, Methods of Psychological Research Online, 8(2), 23-74.

Simsek, Ö. F. (2007). Yapısal Eşitlik Modellemesine Giris Temel Ilkeler ve Lisrel Uygulamalar, (Introduction to structural equation modeling, LISREL applications), Ankara, Ekinoks Pub.

Stepanikova, I., Nie, N.H., \& He, X. (2010). Time on the internet at home, loneliness, and life satisfaction: Evidence from panel time-diary data, Computers in Human Behavior, 26(3), 329-338.

Şahin, C., \& Korkmaz, Ö. (2011). Adaptation of internet addiction scale to Turkish, Selcuk Un. Journal of Ahmet Kelesoğlu Educational Faculty, 32: 101-115.

Tellegen, A., \& Atkinson, G. (1974). Openness to absorbing and self-altering experiences ("Absorption"), a trait related to hypnotic susceptibility, Journal of Abnormal Psychology, 83(3), 268-277).

Turel, O., \& Serenko, A. (2010) Is mobile email addiction overlooked? Communications of the ACM, 53(5), 41-43

Usluel, Y. K. \& Vural, F. K. (2009). Adaptation of cognitive absorption scale to Turkish, Ankara University, Journal of Faculty of Educational Sciences, 42(2), 77-92.

Wainer, J., Dwyer, T., Dutra, R. S., Covic, A., Magalhães, V. B., Ferreira, L. R. R., et al. (2008). Too much computer and internet use is bad for your grades, especially if you are young and poor: results from the 2001. Brazilian SAEB, Computers \& Education, 51, 1417-1429.

Webster, J., \& Hackley, P. (1997). Teaching effectiveness in technology-mediated distance learning, Academy of Management Journal, 40(6), 1282-1309.

Webster, J., \& Ho, H. (1997). Audience engagement in multimedia presentations, Data Base for the Advances in Information Systems, 28(2), 63-77.

Weiss, R. S. (1973). Loneliness: The experience of emotion and social isolation. Cambridge: MIT Press.

Weiss, R. S. (1987). Reflections on the present state of loneliness research, Journal of Social Behaviour and Personality, (2), 1-16.

Wenz, F. V. (1977). Seasonal suicide attempts and forms of loneliness, Psychological Report, 40(3), 807-810.

Wood, J. T. (2007). Gendered lives: Communication, gender, and culture (7th ed.). Belmont, CA: Wadsworth.

Xu,Z., Turel, O., \& Yuan, Y. (2012). Online game addiction among adolescents: motivation and prevention factors,
European Journal of Information Systems, (2012) 21, 321340. doi:10.1057/ejis.2011.56;

Yellowlees, P.M., \& Marks, S. (2007). Problematic Internet use or Internet addiction? Computers in Human Behavior, 23(3), 1447-1453.

Yildirim, M. (2007). An investigation of adolescents that resort to violence and others that do not in terms of degree of loneliness and peer pressure, Unpublished Master's Thesis, Cukurova University, Institute of Social Sciences, Turkey, Number of Thesis: 220627

Young, K. S. (1998). Internet addiction: The emergence of a new clinical disorder, CyberPsychology and Behavior, 1, 237244.

Young, K. S. (1996). Addictive use of the Internet: A case that breaks the stereotype, Psychological Reports, 79: 899902.

Zhang, P., Li, N., \& Sun, H. (2006).Affective Quality and Cognitive Absorption: Extending Technology Acceptance Research, Proceedings of the Hawaii International Conference on System Sciences.

\section{$\diamond \diamond \diamond$}

